\title{
Schwannoma of Posterior Pharyngeal Wall: An Unusual Tumor in an Unusual Location!
}

\author{
${ }^{1}$ Gaurav Ashish, ${ }^{2}$ George A Mathew, ${ }^{3}$ Harshad Parmar
}

\begin{abstract}
Schwannomas of head and neck are classically located in the parapharyngeal space; however, it is rarely located on the posterior pharyngeal wall. Posterior pharyngeal wall schwannomas are thought to originate from the sympathetic nerve plexus. Clinically, this may present as an asymptomatic mass with a constellation of symptoms ranging from globus sensation, dysphagia, to even airway compromise.

We present a rare case of posterior wall schwannoma. It concerns a young woman with a mass in the posterior wall of the pharynx causing globus sensation.
\end{abstract}

Keywords: Head and neck tumors, Neurilemmoma, Posterior pharyngeal wall, Schwannoma.

How to cite this article: Ashish G, Mathew GA, Parmar H. Schwannoma of Posterior Pharyngeal Wall: An Unusual Tumor in an Unusual Location! Int J Otorhinolaryngol Clin 2016;8(1):35-37.

\section{Source of support: Nil}

Conflict of interest: None

\section{INTRODUCTION}

Schwannomas are usually slowing-growing benign neoplasms originating from the neural crest cells. These are usually found in the parapharyngeal region when considering head and neck region and their occurrence in posterior pharyngeal wall is relatively rare. ${ }^{1}$

Schwannomas arise from the perineural sheath of Schwann cells and are, hence, classified as nerve sheath tumors. Schwannomas may be found along any somatic or sympathetic nerve. The head and neck region is a common site for these tumors as there are abundant neural structures and possess unique anatomical compartmentalization. The purpose of this paper is to develop insights

\footnotetext{
${ }^{1}$ Postgraduate Registrar, ${ }^{2}$ Associate Professor, ${ }^{3}$ Assistant Professor

${ }^{1}$ Department of ENT and Head and Neck, Christian Medical College, Vellore, Tamil Nadu, India

${ }^{2}$ Department of ENT, Christian Medical College, Vellore, Tamil Nadu, India

${ }^{3}$ Department of Pathology, Christian Medical College, Vellore Tamil Nadu, India

Corresponding Author: Gaurav Ashish, Postgraduate Registrar Department of ENT and Head and Neck, Christian Medical College, Vellore, Tamil Nadu, India, Phone: +919629329361 e-mail: gauravashish05@gmail.com
}

regarding the diagnosis and treatment of such tumors. Schwannomas on the posterior pharyngeal wall remains a diagnostic challenge due to the nonspecific complaints and examination findings.

\section{CASE REPORT}

A 28-year-old woman was referred to the ENT department, with a 2-year history of globus sensation that was progressively worsening.

On examination, she had a large $(3 \times 2.5 \mathrm{~cm})$ smooth, mass lesion on the posterior pharyngeal wall. The oropharyngeal airway appeared significantly compromised, though she did not complain of any breathing difficulty. Computed tomography (CT) of the neck revealed a large, prevertebral soft tissue mass on the left side measuring approximately $2.5 \times 3 \mathrm{~cm}$ with a "target" appearance (Fig. 1 ). The lesion showed enhancement with contrast (Fig. 2). The lesion was at the level of the oral cavity, compromising the oropharynx (Fig. 3), extending superiorly to just below the fossa of Rosenmueller.

She underwent a complete transoral excision of the lesion under general anesthesia. Histological features demonstrated cells arranged in loose myxoid fashion demonstrating clear margins with spindle-shaped cells arranged uniformly. Similar areas also existed with palisading arrangement of nuclei. The appearance was consistent with a benign schwannoma of Antoni type A (Fig. 4). Immunocytochemical staining confirmed the diagnosis by showing positive immunoreactivity for

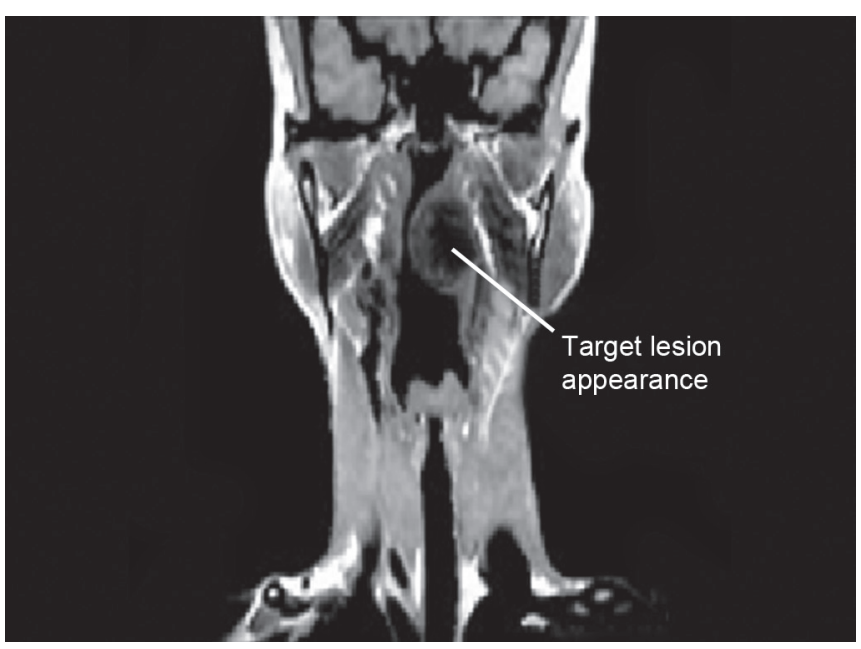

Fig. 1: Target lesion appearance on CT 


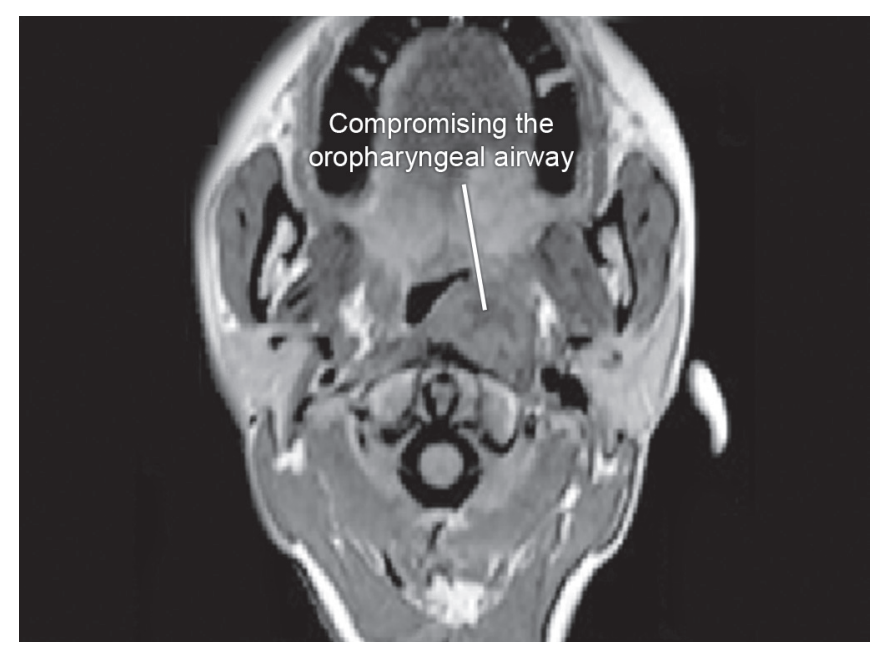

Fig. 2: Enhancement with contrast on CT

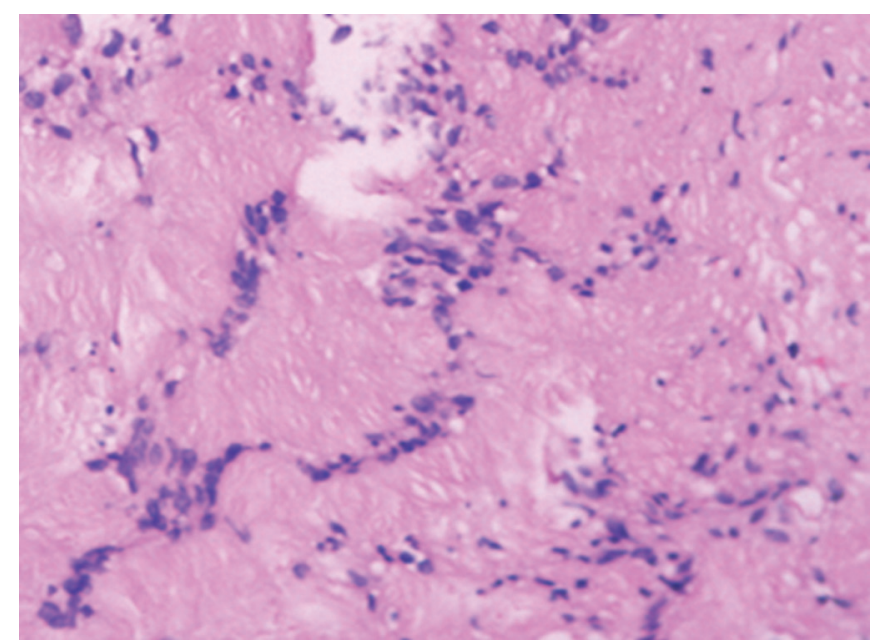

Fig. 4: Sections with $\mathrm{H} / \mathrm{E}$ stain $20 \times$ magnifications showing circumscribed tumor composed of spindle-shaped cells with oval vesicular nuclei and indistinct cell margins, with an orderly arrangement of alternately placed palisades of nuclei and anuclear eosinophilic zones resembling Verocay bodies

S-100 protein (Verocay bodies) (Fig. 5). The histological features were consistent with benign schwannoma. At follow-up after 1 year, there was no evidence of recurrence or residual disease.

\section{DISCUSSION}

Schwannomas are slow-growing tumors arising from Schwann cells, which normally form the nerve sheath. ${ }^{2}$ Schwannomas were first described as a distinct clinical entity in 1908 by Verocay. ${ }^{3}$ It was later established by Stout that these were derived from Schwann cells. ${ }^{4}$

It is commonly seen in females in the age group of 30 to 60 years. ${ }^{5}$ These are usually solitary except in cases of Von Recklinghausen's neurofibromatosis where they are multiple. Schwannomas can occur anywhere in the body with an incidence of 25 to $45 \%$ in head and neck region. ${ }^{6}$ Parapharyngeal space is the commonest location for schwannomas in the head and neck region. The most

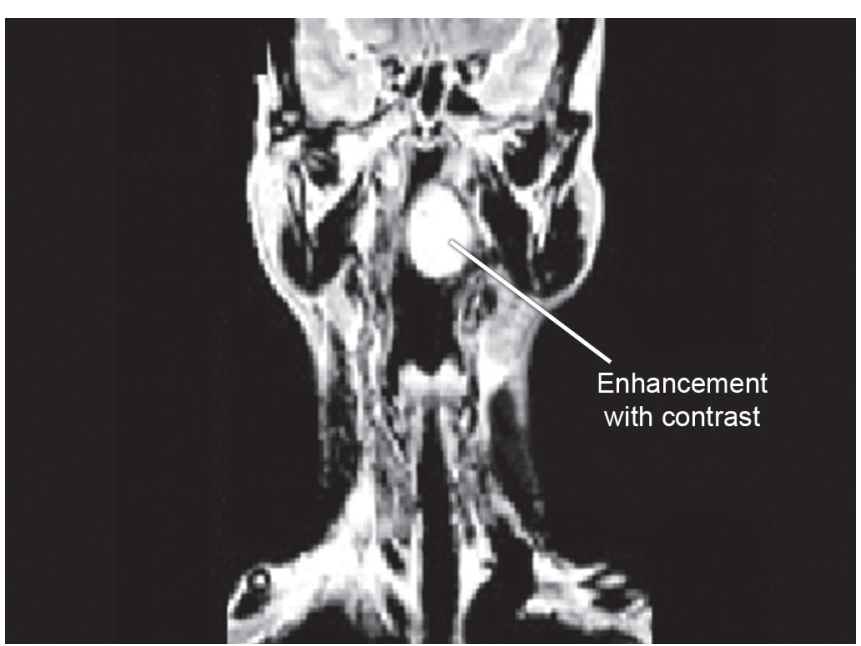

Fig. 3: Oropharyngeal airway compromise

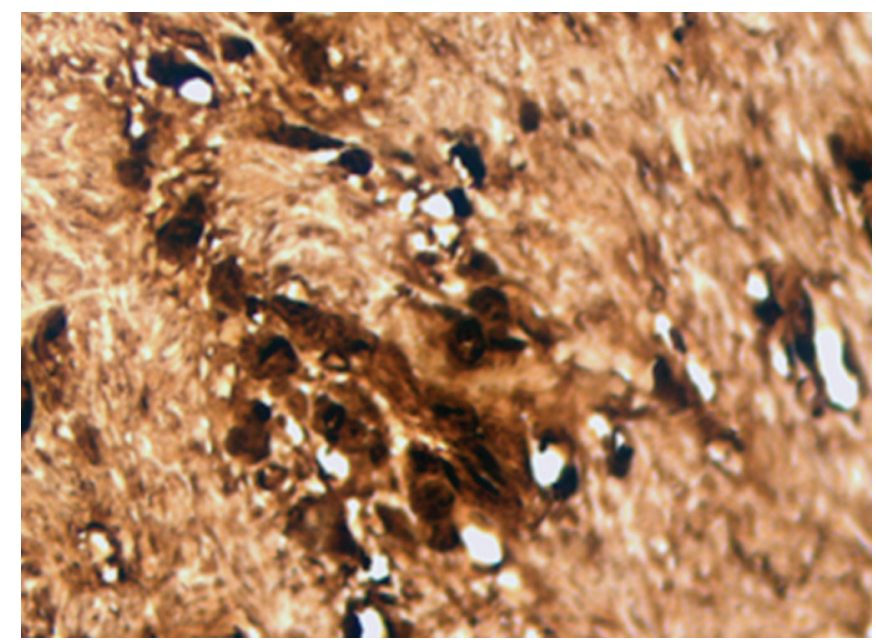

Fig. 5: Cells immunopositive for S-100

frequent nerve of origin is vagus, followed by cervical sympathetic chain. However, its occurrence in prevertebral area is extremely rare and usually arises from the sympathetic nervous plexus.

Schwannomas are mostly asymptomatic and the patients may occasionally present with constellation of symptoms, such as dysphagia, airway compromise, globus sensation, or rarely change in voice.

If patient complains of associated paresthesia, neuralgia, rapid progression in size, or worsening of symptoms, then malignant transformation should be suspected. ${ }^{7}$

A benign posterior pharyngeal wall schwannoma can slowly increase in size, leading to involvement of retropharyngeal and prevertebral space, rarely causing bony destruction of the body of the cervical vertebra by pressure effect. Such cases can be symptomatic, hence, when detected we should aim at in toto excision. ${ }^{8}$

Malignant transformation of benign schwannomas are uncommon but has been reported. Overall incidence 
of malignant transformation in head and neck schwannomas is reported to be approximately 8 to $10 \% .{ }^{9}$ Malignant transformation and high vascularity of such tumors should be ruled out as the management, approach, and outcomes may be different while handling them.

Radiologically, schwannomas have been described as heterogeneous and homogeneous lesions, which can have variable attenuation ranging from hyper- to hypoattenuation with associated enhancement on $\mathrm{CT}^{10}$

Schwannomas are tumors with poor vascular supply, but they can show marked enhancement due to pooling of contrast from poor venous drainage, which falsely projects as enhancing tumor, which was in accordance with our case. ${ }^{11}$

The "target sign" on CT scan for schwannomas is a characteristic sign described in the literature. The target appearance is due to a peculiarity in arrangement wherein, hypercellular Antoni type A bodies are arranged at the center and hypocellular Antoni type B bodies at the periphery. ${ }^{12}$

Histologically, schwannomas are classically composed of two growth patterns, namely, Antoni A and B types. Antoni A is highly cellular, being composed of elongated Schwann cells, which demonstrate a palisading compact pattern. ${ }^{13}$ On the contrary, Antoni B regions are composed of elongated Schwann cells but are arranged in a less dense pattern and are more disorganized. Verocay bodies are regions that are devoid of nuclei between these palisades. ${ }^{14}$ The protein S-100 is the hallmark immunohistochemical marker for identifying the Schwann cells of peripheral nerve sheath tumors. ${ }^{15}$

Few of the differentials in the prevertebral area that have to be ruled out are abscess, lipomatous lesion, sarcoidosis, neurogenic tumors, lymphomas, Forestier's disease, and internal carotid artery aneurysms. ${ }^{16}$

Management of choice for benign schwannomas is in toto surgical excision of the tumor with preservation of the nerve associated as far as possible. ${ }^{4}$

The approach varies according to the location and size of the tumor. Transoral, cervical, transparotid, or a combination of these can be used to address these tumors. Safest approach for the parapharyngeal schwannoma is external, whereas a transoral approach for prevertebral schwannomas is sufficient due to less vascular structures in the proximity. ${ }^{17}$ Recurrence following complete excision of benign is very rare. ${ }^{18}$

\section{CONCLUSION}

Schwannoma of the prevertebral/retropharyngeal region is an extremely rare benign lesion of the head and neck region. Although rare, this should still be considered as one of the probable differentials for prevertebral lesions. The ideal approach for excision of such lesions should be tailored as per the size, site, and extent of the lesion. Transoral excision is the best approach for medium-sized lesions with total resectability and virtually no morbidity. This case is presented in context of developing insights in clinical diagnosis and management of such rare presentation of schwannomas in the head and neck region.

\section{REFERENCES}

1. Triaridis C, Tsalighopoulos MG, Kouloulas A, Vartholomeos A. Posterior pharyngeal wall schwannoma (case report). J Laryngol Otol 1987 Jul;101(7):749-752.

2. Karaca CT, Habesoglu TE, Naiboglu B, Habesoglu M, Oysu C, Egeli E, Tosun I. Schwannoma of the tongue in a child. Am J Otolaryngol 2010 Jan-Feb;31(1):46-48.

3. Mosharrafa TM, Kuppersmith RB, Porter JP, Donovan DT. Pathologic quiz case 1. Malignant peripheral nerve sheath tumor of the ethmoidal sinus. Arch Otolaryngol Head Neck Surg 1997 Jun;123(6):654, 656-657.

4. Leu YS, Chang KC. Extracranial head and neck schwannomas: a review of 8 years experience. Acta Otolaryngol (Stockh) 2002 Jun;122(4):435-437.

5. Lira RB, Gonçalves Filho J, Carvalho GB, Pinto CA, Kowalski LP. Lingual schwannoma: case report and review of the literature. Acta Otorhinolaryngol Ital 2013 Apr;33(2):137-140.

6. Katz AD, Passy V, Kaplan L. Neurogenous neoplasms of major nerves of face and neck. Arch Surg 1971 Jul;103(1):51-56.

7. Weber AL, Montandon C, Robson CD. Neurogenic tumors of the neck. Radiol Clin North Am 2000 Sep;38(5):1077-1090.

8. Singh B, Ramjettan S, Maharaj TP, Ramsaroop R. Schwannoma of the posterior pharyngeal wall. J Laryngol Otol 1995 Sep;109(9):883-885.

9. Enoz M, Suoglu Y, Ilhan R. Lingual schwannoma. J Cancer Res Ther 2006 Jun;2(2):76-78.

10. Silver AJ, Mawad ME, Hilal SK, Ascherl GF, Chynn KY, Baredes S. Computed tomography of the carotid space and related cervical spaces. Part II: Neurogenic tumors. Radiology 1984 Mar 1;150(3):729-735.

11. Som PM, Biller HF, Lawson W, Sacher M, Lanzieri CF. Parapharyngeal space masses: an updated protocol based upon 104 cases. Radiology 1984 Oct 1;153(1):149-156.

12. Murphey MD, Smith WS, Smith SE, Kransdorf MJ, Temple HT. From the archives of the AFIP imaging of musculoskeletal neurogenic tumors: radiologic-pathologic correlation. Radiographics 1999 Sep 1;19(5):1253-1280.

13. Sawhney R, Carron MA, Mathog RH. Tongue base schwannoma: report, review, and unique surgical approach. Am J Otolaryngol 2008 Apr;29(2):119-122.

14. Pfeifle R, Baur DA, Paulino A, Helman J. Schwannoma of the tongue: report of 2 cases. J Oral Maxillofac Surg 2001 Jul;59(7):802-804.

15. Dermatologic Manifestations of Neurilemmoma. 2012 Jun 17 [cited 2013 Oct 19]. Available from: http://emedicine.medscape.com/article/1058342-overview.

16. Kumagai M, EndoS, Shiba K, Masaki T, Kida A, Yamamoto M, Sakata H. Schwannoma of the retropharyngeal space. Tohoku J Exp Med 2006 Oct;210(2):161-164.

17. Bradley N, Bowerman JE. Parapharyngeal neurilemmomas. Br J Oral Maxillofac Surg 1989 Apr;27(2):139-146.

18. Hsu Y-C,Hwang C-F,Hsu R-F, Kuo F-Y, Chien C-Y. Schwannoma (neurilemmoma) of the tongue. Acta Otolaryngol (Stockh) 2006 Aug;126(8):861-865. 